\title{
SKRINING AKTIVITAS ANTIOKSIDAN JAMU SUBUR KANDUNGAN KOMERSIAL
}

\author{
Mujahidin Ahmad \\ Jurusan Biologi, Fakultas Sains dan Teknologi, \\ Universitas Islam Negeri Maulana Malik Ibrahim Malang \\ Email korespondensi: almujahidinahmad@gmail.com
}

\begin{abstract}
ABSTRAK
Selection of traditional medicine is often considered as a choice since the affordable price and low side effects than chemical drugs. One of the well-known herbal medicine produced and consumed in java is Madura Herbal Medicine (MHM). MHM "Subur Kandungan" is one of the original medicinal products which is widely known in inducing fertility, but has not been scientifically standardized so make this many doubt for its usefulness. With the standardization and scientific assessment, MHM ought to be accepted in the modern medical system as well as lead in increasing both society revenues and public health. MHM "Subur Kandungan" consist of garlic (Allium sativum L.), Sweet Flag (Acorus calamus L.), and Intersection rhizome mango (Curcuma mangga Val.) is widely recognized as efficacious herbal medicine for inducing fertility. To determine the potency of those three plants, these were extracted by ethanol and continued by testing the antioxidant potential (DPPH) both individually and mixed. Assessments of phytochemical and antimicrobial potency were discussed. Test results showed that antioxidant activity represented by DPPH IC 50 values of ethanol extract of A. sativum, A. calamus, C. mangga and a mixture of those are 383.56, 335.68, 32.48, $27.773 \mu \mathrm{g} / \mathrm{ml}(\mathrm{ppm})$ respectively. Allium sativum and A.calamus are weak antioxidants as having $I C_{50}$ in the range of 250-500 ppm, while the C. mangga and a mixture of those have strong antioxidant content as having $I_{50}$ of less than $50 \mathrm{ppm}$. Allegedly due to the high antioxidant content of the content of steroids, phenols, tannins, flavonoids, glycosides, diterpene, triterpenes, and alcaloids in A. calamus, also contains steroids, flavonoids, glycosides, diterpene, triterpenes and alaloids on A. sativum and also the presence of terpenoids as compound intersection primary contained in $C$. mangga respectively.
\end{abstract}

Keywords: herbs, antioxidants, A. sativum, A. calamus, C. mangga

\section{PENDAHULUAN}

Kecenderungan dalam pemanfaatan tumbuhan obat ditunjukkan oleh peningkatan nilai perdagangan obat herbal dan suplemen makanan di dunia. Pada tahun 2000 nilai perdagangan bisa mencapai US\$ 40 milyar, tetapi pada tahun 2002 meningkat menjadi US\$ 60 milyar (Allorerung et al., 2005). Pada tahun 2050 peningkatan nilai perdagangan tumbuhan obat ini diperkirakan menjadi US\$ 5 triliun dengan asumsi peningkatan per tahun sebesar $15 \%$. Di Indonesia sendiri volume perdagangan obat tradisional pada tahun 2005 mencapai $\mathrm{Rp}$ 2,9 triliun dan diperkirakan pada 2010 mencapai Rp 7,2 triliun dengan asumsi peningkatan per tahun sebesar 12 persen (Anonim, 2006).
Indonesia merupakan salah satu negara yang kaya akan keanekaragaman hayati. Kekayaan jenis tumbuhan Indonesia berjumlah sekitar 37.000 spesies tumbuhan (Schumacher, 1996 dalam Erdelen et al., 1999). Sebanyak 940 jenis tumbuhan telah terdaftar sebagai penyedia bahan ramuan untuk keperluan pengobatan secara tradisional (Rifa'i, 2000; Bermawie et al., 2005). Menurut Zuhud (2003), kurang lebih 400 kelompok etnis masyarakat Indonesia memiliki hubungan yang erat dengan tumbuhan obat, di antaranya kelompok etnis Madura.

Madura dikenal sebagai salah satu etnik yang memiliki kekayaan pengetahuan tradisional dalam bidang obat tradisional atau "jamu" khususnya yang berkaitan dengan keharmonisan suami istri (Handayani dan 
Sukirno, 2000). Walaupun demikian, kekayaan etnik Madura dalam bidang pengobatan sesungguhnya lebih luas dari sekedar upaya menjaga kesehatan reproduksi tersebut. Pengetahuan penting lainnya dalam pengobatan tradisional meliputi; pengetahuan tentang klasifikasi penyakit dan sifat tanaman obat, cara-cara pengobatan, cara perawatan tubuh, jenis-jenis tanaman obat, bahkan jamu untuk sapi (Jordaan, 1985 dalam Purwanti, 2001).

C. mangga, A. calamus, dan A. sativum yang diramu menjadi jamu dikenal dengan "jamu subur kandungan", diyakini menjawab solusi infertilitas wanita. Kandungan fitokimia, aktivitas antioksidan, dan aktivitas antimikroba dari tumbuhan penyusun utama ramuan Madura "subur kandungan" tersebut dianggap menjadi faktor penting dalam meningkatkan fertilitas wanita yang telah dipercaya masyarakat selama ratusan tahun dalam pengobatan tradisional. Oleh karenanya penelitian terkait standardisasi dan saintifikasi jamu Madura berkhasiat kesuburan sangat penting untuk dilakukan. Penelitian akan dilakukan secara bertahap (setiap tahap direncanakan 1 tahun); tahap pertama yaitu skrining zat bioaktif dan fitokimia, aktivitas antioksidan dan antimikroba, baik secara kuantitatif atau kualitatif, tahap kedua yaitu optimasi kombinasi dosis terbaik dan uji secara invitro, tahap ketiga yaitu optimasi kombinasi dosis terbaik dan diuji secara invivo.

Dengan tiga tahapan penelitian diatas diharapkan dapat menjadi dasar saintifikasi jamu tradisional subur kandungan sehingga dapat diterima dalam oleh sistem pengobatan dan masyarakat modern yang pada akhirnya akan mampu meningkatkan pendapatan serta kesehatan masyarakat.

\section{MATERI DAN METODE}

\section{Preparasi bahan Jamu Racik Subur Kandungan}

Penelitian telah dilaksanakan pada bulan Mei-Oktober 2014 di laboratorium Kimia, dan Biologi Fakultas Sains dan Teknologi Universitas Islam Maulana Malik Ibrahim Malang. Jenis penelitian ini adalah penelitian eksploratif dan kuantitatif.

Jamu Madura "Subur Kandungan" memiliki komposisi utama $C$. mangga, $A$. calamus, dan A. sativum diramu menjadi jamu dikenal dengan "jamu subur kandungan" dengan Proporsi (\%) rimpang A. calamus sebanyak $28 \%$, rimpang $C$. mangga sebanyak $36 \%$ dan umbi A. sativum sebanyak $36 \%$ sesuai dengan kandungan tercantum dalam kemasan jamu. Proporsi racikan ini diperoleh dari komposisi bahan "Jamu Subur Kandungan Madura" komersial yang dijual di pasaran.

\section{Ekstraksi Bahan Baku}

Sampel Serbuk (simplisia) berupa rimpang jeringau (A. calamus), rimpang temu manga ( $C$. mangga) dan umbi bawang putih (A. sativum) diperoleh dari balai Materia Medika Kota Batu dalam bentuk simplisia kering

Bahan-bahan berupa rimpang A. calamus, rimpang $C$. mangga sebanyak dan umbi $A$. sativum racik disiapkan dan dilakukan proses ekstraksi, baik secara individu atau campuran.

Ekstraksi komponen aktif dilakukan dengan metode modifikasi dari Rita (2008) menggunakan ekstraksi maserasi/perendaman dengan etanol 70\%. Ekstraksi dilakukan sebanyak 3 kali pengulangan yang dimungkinkan kandungan senyawa dari bahan jamu sudah banyak terekstrak. Bahan jamu (individu dan racikan) ditimbang masingmasing sebanyak $60 \mathrm{~g}$, lalu diekstraksi dengan perendaman menggunakan $300 \mathrm{~mL}$ pelarut etanol p.a. selama 24 jam, kemudian dishaker selama 3 jam, kemudian disaring dan ampas yang diperoleh dimaserasi kembali dengan pelarut yang sama dan dilakukan sebanyak 3 kali pengulangan sampai filtratnya berwarna bening. Selanjutnya disaring dan ampasnya dikeringkan pada suhu ruang hingga terbebas dari pelarut etanol p.a, sedangkan ketiga filtratnya digabung menjadi satu.

Ampas yang telah kering dilakukan peredaman kembali menggunakan pelarut etanol p.a $300 \mathrm{~mL}$ selama 24 jam, kemudian dishaker selama 3 jam, kemudian disaring dan ampas yang diperoleh dimaserasi kembali dengan pelarut yang sama dan dilakukan sebanyak 3 kali pengulangan sampai filtrat yang berwarna bening. Selanjutnya disaring dan ampasnya dikeringkan pada suhu ruang hingga terbebas dari pelarut etanol, sedangkan ketiga filtratnya digabung menjadi satu. Selanjutnya ampas yang telah kering direndam kembali menggunakan pelarut etanol $70 \% 300 \mathrm{~mL}$ selama 24 jam, kemudian dishaker selama 3 jam, kemudian disaring dan ampas yang diperoleh dimaserasi kembali dengan pelarut yang sama dan dilakukan sebanyak 3 kali pengulangan sampai filtrat yang berwarna bening. Selanjutnya disaring dan ampasnya 
dikeringkan pada suhu ruang hingga terbebas dari pelarut etanol $70 \%$, sedangkan ketiga filtratnya digabung menjadi satu.

Keempat ekstrak yang diperoleh masingmasing dipekatkan dengan rotary evaporator sampai diperoleh ekstrak pekat etanol jamu, baik individu maupun racik. Keempat ekstrak pekat yang diperoleh selanjutnya diuji uji diuji kandungan antioksidannya dengan metode DPPH.

\section{Penentuan Kemampuan Aktivitas Antioksidan Ekstrak Tanaman Dalam Peredaman Radikal Bebas Dengan Metode DPPH}

Penentuan aktifitas penangkap radikal simplisia jamu subur kandungan dilakukan sesuai metode Cholisoh dan Utami (2008) yang dimodifikasi sebagaimana berikut; diawali dengan pembuatan Pembuatan Trisma $\mathrm{HCl}$ 0,05 M dengan dengan $\mathrm{pH} 7,4$. Caranya adalah dengan menimbang $394,0 \mathrm{mg}$ trisma $\mathrm{HCl}$ kemudian dilarutkan dengan aqua bides dalam labu takar 50,0 ml, sehingga diperoleh konsentrasi 0,05 M, larutan disesuaikan $\mathrm{pH}$-nya menjadi 7,4 .

Selanjutnya adalah pembuatan Larutan stok DPPH dengan dengan konsentrasi konsentrasi 0,1m M; sebanyak 1,969 mg DPPH ditimbang dan dilarutkan dengan etanol sampai tanda pada labu takar $25 \mathrm{ml}$, sehingga diperoleh konsentrasi 0,2 $\mathrm{mM}$. Larutan ini disimpan dalam almari es dan hendaknya dipakai sesegera mungkin.

Penentuan Operating Time (OT). Larutan stok DPPH diambil sebanyak 2,0 ml dan ditempatkan dalam labu takar 5,0 ml, kemudian ditambah 0,5 ml larutan dapar trisma $\mathrm{HCl}$ dan ditambah 5001 larutan ekstrak jamu dengan konsentrasi $2 \%$, lalu ditambahkan etanol sampai tanda, kemudian di vorteks selama 2 menit. Penentuan operating time dilakukan pada pembacaan pada panjang gelombang $517 \mathrm{~nm}$ dengan spektrofotomrter UVis dengan interval waktu 5 menit sampai didapat absorbsansi yang stabil, tidak terlihat adanya penurunan absorbansi. Blangko yang digunakan adalah $2 \mathrm{ml}$ larutan jamu dengan konsentrasi $2 \%, 0,5 \mathrm{ml}$ trisma $\mathrm{HCl}$ dan etanol $5,0 \mathrm{ml}$. Waktu yang diperoleh digunakan juga untuk vitamin $\mathrm{C}$.

Pembuatan seri konsentrasi ekstrak etanol bawang putih, jeringau, temu mangga dan ramuan jamu ditimbang saksama 20,0 mg dalam botol timbang kemudian ditambah etanol sebagai pelarut dan divorteks, setelah semua terlarut dipindahkan dalam labu takar 10,0 ml dan ditambahkan etanol sampai tanda, Sehingga didapatkan larutan stok 0,2 \% b/v. Dari larutan stok dibuat 5 seri konsentrasi yaitu 200 ppm, 100 ppm, 50 ppm, 25 ppm, dan 12.5 ppm yang dilarutkan dalam etanol.

Uji aktivitas penangkap radikal bawang putih, jeringau, temu mangga dan ramuan jamu dilakukan dengan menambahkan $750 \mu \mathrm{l}$ sampel, $600 \mu \mathrm{l}$ DPPH dan $150 \mu \mathrm{l}$ Tris $\mathrm{HCl}$ ke dalam 2 $\mathrm{ml}$ eppendorf tube sehingga volume total dalam tube adalah $1.5 \mathrm{ml}$. Blangko didapat dengan menambahkan tris, sampel dan pelarut, sedangkan kontrol didapat dengan menambahkan tris dalam pelarut dan DPPH. Semua sampel divortex selama 2 menit dan di inkubasi pada suhu $37^{\circ} \mathrm{C}$ dalam inkubator selama 30 menit. Selanjutnya diukur absorbansi di Spektrofotometer UV-Vis pada panjang gelombang $517 \mathrm{~nm}$. Semua sampel dibaca sebanyak 3 kali

Cara Analisis Penentuan aktifitas Penangkap Radikal. Hasil aktivitas penangkap radikal fraksi dari ekstrak daun pandan dibandingkan dengan vitamin C. Besarnya aktivitas penangkap radikal dihitung dengan rumus:

Persen $(\%)$ penangkap radikal $=$

$\left(\frac{\text { Absorbansi kontrol -Absorbansi sampel }}{\text { Absorbansi Kontrol }}\right)$ X $100 \%$

dan dilakukan perhitungan $\mathrm{IC}_{50}$, yakni suatu nilai yang menggambarkan besarnya konsentrasi fraksi dari ekstrak uji yang dapat menangkap radikal bebas sebesar 50\% melalui persamaan garis regresi linier yang menyatakan hubungan antara konsentrasi senyawa (sampel) uji (X) dengan aktivitas penangkap radikal ratarata (Y) dari seri replikasi pengukuran. Semakin kecil nilai $\mathrm{IC}_{50}$ nya maka senyawa uji tersebut mempunyai keefektifan sebagai penangkap radikal yang lebih baik.

\section{HASIL DAN PEMBAHASAN}

Berdasarkan hasil uji antioksidan yang didapat diketahui bahwa antioksidan sintetis yaitu BHT dan vitamin $\mathrm{C}$ didapat nilai $\mathrm{IC}_{50}$ antioksidan vitamin $\mathrm{C}$ dan BHT masing-masing adalah 3,74 dan 4,91 yang menunjukkan bahwa keduanya termasuk antioksidan sangat kuat 
sebagaimana dilaporkan oleh Cholisoh dan Utami (1993). Keduanya merupakan antioksidan kuat karena memiliki nilai $\mathrm{IC}_{50}$ kurang dari 50 ppm. Sebagaimana menurut Jun dkk. (2003) dalam Samin dkk. (2012) bahwa tingkat kekuatan antioksidan dikatakan kuat jika $\mathrm{IC}_{50}<50$ ppm, aktif ( $\mathrm{IC}_{50} 50-100$ ppm), sedang ( $\left.\mathrm{IC}_{50} 101-250 \mathrm{ppm}\right)$, Lemah ( $\mathrm{IC}_{50} 250$ 500 ppm), dan tidak aktif ( $\mathrm{IC}_{50}>500$ ppm).
Selanjutnya nilai $\mathrm{IC}_{50}$ untuk ekstrak etanol dari jamu subur kandungan (hasil racikan sendiri) adalah sebagaimana disajikan dalam tabel 2. Hasil uji menunjukkan bahwa ekstrak etanol jamu hasil racikan sendiri memiliki nilai $\mathrm{IC}_{50}$ sebesar $27.77 \quad 67 \mu \mathrm{g} / \mathrm{ml}$. Sehingga keduanya termasuk dalam kategori antioksidan kuat. Hasil tersebut disajikan pada tabel 1.

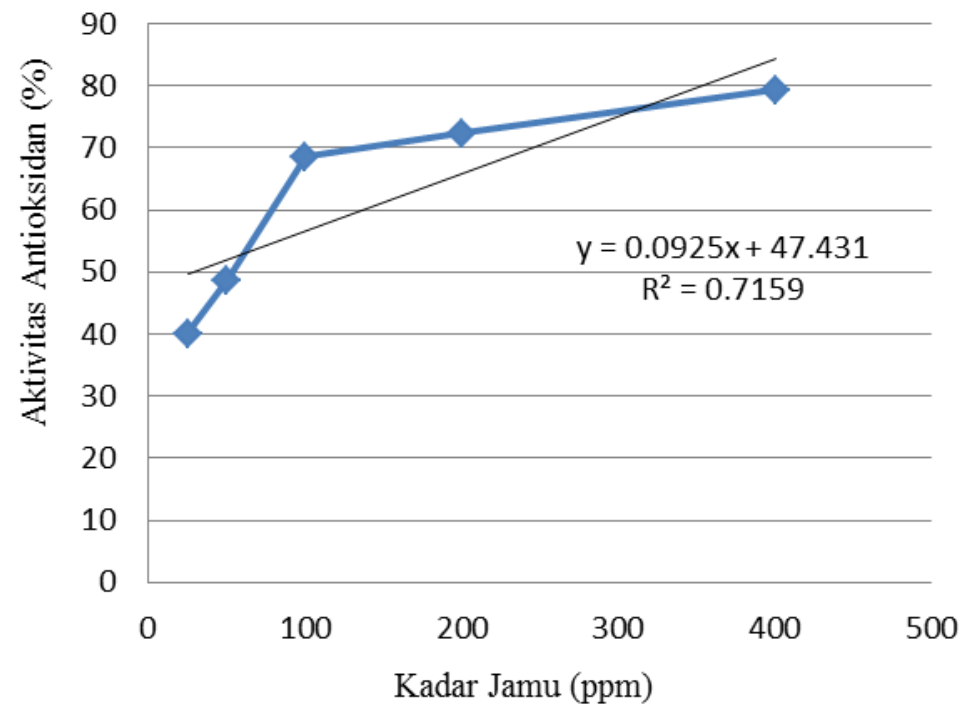

Gambar 1. Pengaruh konsentrasi jamu terhadap level aktivitas antioksidan

Tabel 1. Hasil uji antioksidan metode DPPH rimpang C. mangga, ekstrak etanol rimpang $A$. calamus, dan umbi A. sativum dan kombinasinya (jamu)

\begin{tabular}{|c|c|c|c|c|}
\hline Bahan & $\begin{array}{c}\text { Konsentrasi } \\
\mu \mathrm{g} / \mathrm{ml}\end{array}$ & $\begin{array}{c}\text { Aktivitas } \\
\text { penangkap } \\
\text { Radikal (\%) }\end{array}$ & $\begin{array}{c}\text { Persamaan } \\
\text { Regresi Linier }\end{array}$ & $\begin{array}{c}\mathrm{IC}_{50} \\
\mu \mathrm{g} / \mathrm{ml}\end{array}$ \\
\hline \multirow{5}{*}{$\begin{array}{c}\text { Ekstrak } \\
\text { Etanol } \\
\text { Jamu } \\
\text { (kombinasi } \\
\text { 3 bahan) }\end{array}$} & 25 & 40.02 & \multirow{5}{*}{$\begin{array}{c}y=0.0925 x+47.431 \\
R^{2}=0.7159\end{array}$} & \multirow{5}{*}{27.773} \\
\hline & 50 & 48.61 & & \\
\hline & 100 & 68.56 & & \\
\hline & 200 & 72.35 & & \\
\hline & 400 & 79.26 & & \\
\hline
\end{tabular}

Berdasarkan hasil uji DPPH diatas dapat dikatakan bahwa jamu subur kandungan berkomposisi bawang putih, jeringau, dan temu mangga memiliki potensi antioksidan kuat karena memiliki $\mathrm{IC}_{50}$ (berada di bawah 50 ppm), hal ini sebagaimana menurut Jun dkk. (2003) dalam Samin dkk. (2012). 
Tabel 2. Hasil uji antioksidan metode DPPH rimpang temu manga (C. mangga), ekstrak etanol rimpang jeringau (A. calamus), dan umbi bawang putih (A. sativum) dan kombinasinya (jamu)

\begin{tabular}{|c|c|c|c|c|}
\hline Bahan & $\begin{array}{c}\text { Konsentrasi } \\
\mu \mathrm{g} / \mathrm{ml}\end{array}$ & $\begin{array}{c}\text { Aktivitas } \\
\text { penangkap } \\
\text { Radikal (\%) } \\
\end{array}$ & $\begin{array}{c}\text { Persamaan } \\
\text { Regresi Linier }\end{array}$ & $\begin{array}{c}\mathrm{IC}_{50} \\
\mu \mathrm{g} / \mathrm{ml}\end{array}$ \\
\hline \multirow{5}{*}{$\begin{array}{c}\text { Ekstrak } \\
\text { etanol } \\
\text { Bawang } \\
\text { Putih }\end{array}$} & 25 & 18.95 & \multirow{5}{*}{$\begin{array}{c}y=0.0738 x+21.693 \\
R^{2}=0.8935\end{array}$} & \multirow{5}{*}{383.56} \\
\hline & 50 & 25.31 & & \\
\hline & 100 & 31.55 & & \\
\hline & 200 & 41.47 & & \\
\hline & 400 & 48.38 & & \\
\hline \multirow{5}{*}{$\begin{array}{c}\text { Ekstrak } \\
\text { etanol } \\
\text { Jeringau }\end{array}$} & 25 & 19.06 & \multirow{5}{*}{$\begin{array}{c}\mathrm{y}=0.0914 \mathrm{x}+19.319 \\
\mathrm{R}^{2}=0.9788\end{array}$} & \multirow{5}{*}{335.678} \\
\hline & 50 & 23.63 & & \\
\hline & 100 & 31.44 & & \\
\hline & 200 & 38.35 & & \\
\hline & 400 & 54.96 & & \\
\hline \multirow{5}{*}{$\begin{array}{c}\text { Ekstrak } \\
\text { Etanol } \\
\text { Temu } \\
\text { Mangga }\end{array}$} & 25 & 31.88 & \multirow{5}{*}{$\begin{array}{c}y=0.2748 x+41.074 \\
R^{2}=0.7045\end{array}$} & \multirow{5}{*}{32.482} \\
\hline & 50 & 65.22 & & \\
\hline & 100 & 81.05 & & \\
\hline & 200 & 89.19 & & \\
\hline & 400 & 79.49 & & \\
\hline \multirow{5}{*}{$\begin{array}{c}\text { Ekstrak } \\
\text { Etanol } \\
\text { Jamu } \\
\text { (kombinasi } \\
\text { 3 bahan) }\end{array}$} & 25 & 40.02 & \multirow{5}{*}{$\begin{array}{c}\mathrm{y}=0.0925 \mathrm{x}+47.431 \\
\mathrm{R}^{2}=0.7159\end{array}$} & \multirow{5}{*}{27.773} \\
\hline & 50 & 48.61 & & \\
\hline & 100 & 68.56 & & \\
\hline & 200 & 72.35 & & \\
\hline & 400 & 79.26 & & \\
\hline
\end{tabular}

Kontribusi tingginya aktivitas antioksidan jamu subur kandungan kemungkinan berasal $A$. sativum yang berdasar uji DPPH memiliki nilai $\mathrm{IC}_{50} 383.56 \mu \mathrm{g} / \mathrm{mL}$ (tabel 2). Angka ini sedikit lebih tinggi dari penelitian Ifesan et al., (2014), yang menyatakan bahwa bawang putih memiliki total fenol atau aktivitas antioksidan $355 \mu \mathrm{g} / \mathrm{ml}$. Sedangkan menurut Aqil, Ahmad dan Mehmood (2008) menyatakan bahwa bawang putih memiliki $\mathrm{IC}_{50}$ sebesar $79 \mu \mathrm{g} / \mathrm{mL}$ dengan total fenol sekitar $28,66 \%$ dari zat aktif diuji.

Kontribusi jamu racik subur kandungan juga diduga berasal dari A. calamus yang memiliki antioksidan rendah yaitu ber-IC 50 $335.67 \mu \mathrm{g} / \mathrm{mL}$ (tabel 2). Jauh berbeda dengan hasil penelitian (Barua et al., 2014) yang menyebutkan aktivitas antioksidan berdasar $\mathrm{IC}_{50} \mathrm{DPPH}$ adalah $A$. calamus adalah 54.82 $\mu \mathrm{g} / \mathrm{ml}$. Menurut Barua et al. (2014), kandungan fitokimia yang menonjol pada A. calamus, meliputi steroid, fenol, tannin, flavonoid, glikosida, diterpen, triterpen dan alkaloid.

Berikutnya, tingginya aktivitas antioksidan jamu subur kandungan juga dipengaruhi oleh keberadaan temu mangga yang juga dikenal memiliki antioksidan yang tinggi. Menurut Sarjono dan Mulyani (2007), komponen utama yang berkhasiat diantaranya sebagai antioksidan dalam rimpang temu mangga adalah kurkuminoid, flavonoid, polifenol dan minyak atsiri. Pada $C$. mangga ditemukan bahan bioaktif yang sangat menonjol, diantaranya adalah caryophyllene oxide $(18.71 \%)$ dan caryophyllene (12.69\%) yang mendominasi pada bagian minyak $C$. mangga (Malar, 2011). C. mangga juga dilaporkan oleh Pujimulyani et al. (2012) mengandung fenol, flavonoid, dan tanin. Pada penelitian ini didapat melalui uji DPPH bahwa nilai $\mathrm{IC}_{50}$ temu mangga adalah $32.482 \mu \mathrm{g} / \mathrm{mL}$ (tabel 2). 
Kandungan antioksidan yang tinggi pada jamu "subur kandungan" dapat dikatakan berasal dari keberadaan kandungan steroids, fenol, tannin, flavonoid, glikosida, diterpene, triterpen dan alkaloid pada A. calamus (Barua et al., 2014), juga kandungan steroids, flavonoid, glikosida, diterpene, triterpen dan alkaloid pada A. sativum (Gazuwa et al, 2013) dan juga adanya terpenoids sebagai senyawa utama yang terdapat pada $C$. mangga (Tarigan dkk, 2008) sebagaimana penelitian terdahulu.

\section{KESIMPULAN DAN SARAN}

Dapat disimpulkan bahwa jamu subur kandungan sangat berpotensi untuk obat fertilitas karena memiliki kandungan aktivitas antioksidan golongan kuat dengan nilai $\mathrm{IC}_{50}$ $27.77 \mu \mathrm{g} / \mathrm{ml}$ yang dimungkinan karena adanya kontribusi steroids, fenol, tannin, flavonoid, glikosida, diterpene, triterpen dan alkaloid pada A. calamus dan A. sativum, juga adanya Terpenoids sebagai senyawa utama yang terdapat pada C. mangga sebagaimana penelitian terdahulu.

Disarankan untuk dilakukan penelitian lanjutan dengan melakukan uji fitokimia dan antibakteri atas ketiga bahan dan ramuan tersebut.

\section{UCAPAN TERIMAKASIH}

Kami ucapkan terimakasih kepada LP2M Universitas Islam Negeri Maulana Malik Ibrahim Malang sebagai pemberi dukungan dana penelitian ini dan Tim Riset Biofarmaka FST Universitas Islam Negeri Maulana Malik Ibrahim Malang atas kerjasama dan dukungan moralnya.

\section{DAFTAR PUSTAKA}

Allorerung, D., Kemala, S., Rostiana, O., Rizal, M., Rahardjo, M., Yuliani, S. dan Sugiharto. 2005. Prospek dan Arah Pengembangan Agribisnis Tanaman obat. Badan Penelitian dan Pengembangan Pertanian. Departemen Pertanian.

Anonim, 2006. Pasar Obat Herbal Meningkat Pesat. http://www.bppt.go.id.

Aqil, F., Ahmad, I., \& Mehmood, Z. 2006. Antioxidant and Free Radical Scavenging Properties of Twelve Traditionally Used Indian Medicinal Plants, 30, 177-183.
Barua, C. C., Sen, S., Das, A. S., \& Talukdar, A. 2014. A comparative study of the in vitro antioxidant property of different extracts of Acorus calamus Linn, 4(1), 8-18.

Bermawie, N., Hernani, Suwijiyo P. and Kardono, L.B.S. 2005. Approaches For Sustainable Utilization of Biodiversity of Medicinal and Aromatic Plants in Indonesia. http://dbp.gov.my/mab2005/.

Cholisoh, Z dan Utami , W., 2008, Aktivitas Penangkap Radikal Ekstrak Ethanol 70\% Biji Jengkol (Archidendron Jiringa). Fakultas Farmasi Universitas Muhammadiyah Surakarta. PHARMACON, Vol. 9, No. 1, Juni 2008, 33-40

Erdelen, W. R., Adimihardja, K., Moesdarsono, H., and Sidik. 1999. Biodiversity, Traditional Medicine and The Sustainable Use of Indigenous Medicinal Plants in Indonesia. Indigenous Knowledge Development Monitor. 7 (3): 3-5.

Gazuwa, S. Y., Makanjuola, E. R., Jaryum, K. H., Kutshik, J. R., \& Mafulul, S. G. 2013. The Phytochemical Composition of Allium Cepa / Allium Sativum and the Effects of Their Aqueous Extracts ( Cooked and Raw Forms ) on The Lipid Profile and other Hepatic Biochemical Parameters in Female Albino Wistar Rats ., 4(3), 406-410.

Handayani, L dan S. Sukirno. 2000. Pemanfaatan Jamu Rapat dan Keputihan serta Tradisi yang Menyertai Pada Masyarakat Madura. Dalam: Purwanto dan Walujo, E.B. (eds). Prosiding Seminar Lokakarya Nasional Etnobotani III Denpasar Bali. Hal 344-350.

Ifesan, B. O. T., Fadipe, E. A., \& Ifesan, B. T. 2014. Investigation of Antioxidant and Antimicrobial Properties of Garlic Peel Extract ( Allium sativum ) and Its Use as Natural Food Additive in Cooked Beef, 3(5), 711-721.Jawetz, E., Melnick, J., Adelberg, E. 1996. Mikrobiologi Kedokteran, Ed.20. Jakarta : EGC;14:211-7

Pujimulyani, D., Raharjo, S., Marsono, Y., \& Santoso, U. (n.d.). ( Curcuma mangga Val .) SEGAR DAN SETELAH 
BLANCHING The Antioxidant

Activity and Phenolic Content of Fresh and Blanched White Saffron, 100.

Purwanti, U. 2001. Pengembangan Tumbuhan Obat Berbasis Masyarakat di Pulau Madura. Program Warta KEHATI Edisi Januari 2001.

Rifa'i, M.A. 2000. Pingit, Pijet dan Pepahit: Peran Tumbuhan dalam Kosmetik Tradisional Indonesia seperti Dicerminkan di Daerah Madura. http://dbp.gov.my/mab2000/Penerbita n/Rampak/rspijet21.pdf.

Rita, W, S. 2010. Isolasi, Identifikasi, dan Uji Aktivitas Antibakteri Senyawa Golongan Triterpenoid pada Rimpang Temu Putih (Curcuma zedoaria (Berg.) Roscoe. Jurnal Kimia FMIPA. Bukit Jimbaran: Universitas Udayana.

Samin, A.A, Bialangi, N dan Salimi, YK. 2013. Penentuan Kandungan Fenolik Total Dan Aktivitas antioksidan dari Rambut Jagung (Zea Mays L.)Yang Tumbuh Di Daerahgorontalo Jurusan Pendidikan Kimia Fakultas Matematika dan IPA Universitas Negeri Gorontalo

Sarjono, P. R. dan Mulyani, N. S. 2007. Aktivitas Antibakteri Rimpang Temu Putih (Curcuma mangga Vall). Jurnal Sains \& Matematika (JSM), 15(2), pp 89-93

Tarigan, JB, Zuhra, C. F dan Sihotang, H. 2008. Skrining fitokimia tumbuhan yang digunakan oleh pedagang jamu gendong untuk merawat kulit wajah di kecamatan medan baru, Jurnal Biologi Sumatera, Januari 2008, ISSN 19075537 3(1), 1-6.

Zuhud, A. 2003. Pengembangan Tumbuhan Obat Berbasis Konsep Bioregional (contoh kasus di kawasan meru betiri jawa timur). Makalah Filsafat Sains. Program Pascasarjana IPB Bogor. 